\title{
Os Desafios do Ensino Frente à Tradição Iluminista
}

\author{
SIDNEY REINALDO SILVA \\ Doutor em Filosofia pelo IFCH da UNICAMP; Professor do Mestrado em \\ Educação da Universidade Tuiuti do Paraná - UTP \\ sreinald@uol.com.br
}

\begin{abstract}
Resumo
O resgate teórico da relação entre instrução e civilização proposta pelos Enciclopedistas, na segunda metade do século XVIII, tem muito a contribuir para com o atual debate entre as concepções liberais e comunitárias da educação. Para Condorcet, que estava ligado àquele movimento filosófico, a civilização constitui-se em uma ampla perspectiva cultural capaz de sobrepujar as diferenças mais profundas entre os povos e de impor um padrão homogêneo ao modo de ser das nações. Assim, civilizar é também formar a razão e a moral dos povos. Sujeita a perfectibilidade, a humanidade estaria condenada a manter-se progredindo ou a perder suas conquistas. Portanto, a civilização, embora seja a expressão maior do progresso do espírito humano, estaria sempre ameaçada pela barbárie. O progresso resultaria da necessidade de superação racional das tradições dos povos. A civilização seria um critério de avaliação.

Palavras-chave: educação, civilização, tradição, modernidade.
\end{abstract}

\section{Resumen}

El resgate teórico de la relación entre instrucción y civilización propuesta por los Enciclopedistas en la segunda mitad del siglo XVIII, contribuye mucho al debate actual entre las concepciones liberales y comunitarias de la educación. Para Condorcet, que estaba vinculado a aquel movimiento filosófico, la civilización se constituye en una amplia prespectiva cultural capaz de ultrapasar las diferencias mas profundas entre los pueblos y de imponer un modelo homogéneo a la manera de ser de las naciones.De esta forma, civilizar es también trabajar la razón y la moral de los pueblos. Sujeta a irse perfeccionando, la humanidad estaría condenada a ir progresando o a perder sus conquistas. Por eso, la civilización, aunque sea la mayor expresión del progreso del espíritu humano, siempre estará amenazada por la barbarie. El progreso sería el resultado de la necesidad de la superación racional de la tradiciones de los pueblos. La civilización sería un criterio de evaluación.

Palabras-clave: educación , civilización, tradición, modernidad.

\begin{abstract}
The French Encyclopedists' conception of the educational role of the civilization is an interesting standpoint to analyze the ideological dispute between liberal and communitarian educational projects. This paper offers a schematic presentation of Condorcet's criticisms of tradition as a guide for public instruction. He believes that civilization must keep overcoming the traditional patterns of action, otherwise social progress is blocked, and the
\end{abstract}


"barbarian" ways of living will dominate the nations. The only way of avoiding this is a kind of public instruction that shapes the reason and moral of the peoples. Thus public instruction must teach the universality of reason and its cosmopolitan values.

Key words: education, civilization, tradition, modernity. 


\title{
INTRODUÇÃO
}

\author{
"Instruir uma nação é civilizá-la."
}

(Diderot, 1966, p.429)

Este texto correlaciona os ideais de civilização e de instrução no pensamento dos Enciclopedistas, em especial na obra de Condorcet ${ }^{1}$ (17431794). Este autor propôs uma moral baseada em uma suposta identidade geral do ser humano, sobretudo na sensibilidade comum e na universalidade da razão. Ele foi um entusiasta do poder de emancipação inerente à dimensão pedagógica do processo civilizador. Sua proposta de instrução é apresentada como uma forma de ensino capaz de promover uma moral cosmopolita, baseada na razão, na justiça e na simpatia ou benevolência.

A civilização, na concepção cordorcetiana, constitui-se em uma ampla perspectiva cultural capaz de subsumir as diferenças mais profundas entre os povos e de impor um padrão homogêneo ao modo de ser das nações. Ela expandir-se-ia como uma forma de supressão da "barbárie" ou dos costumes inferiores ou atrasados em relação aos avanços do conhecimento racional e aos valores supostamente universais que nações européias já reconheciam e adotavam. A civilização torna-se um critério de avaliação. No Tableau historique des progrès de l'esprit humain, que acabou sendo apresentado em 1793 apenas na forma de uma Esquisse com uma série de fragments, Condorcet narra os progressos passados do

\footnotetext{
1 Jean-Antoine Nicolas de Caritat, o Marquês de Condorcet, nasceu no dia 17 de setembro de 1743, em Ribemont (Aisne). Fez seus primeiros estudos no colégio jesuíta de Reims. Em 1758, entrou para o colégio jesuíta de Navarra. Neste período, ele se interessou pela Matemática, destacando-se, aos 15 anos, com uma tese que despertou a atenção do grande matemático e enciclopedista d'Alembert (1717-1783). Renunciando à carreira militar e à tradição familiar, em 1762, ele foi para Paris, onde continuou estudando a Matemática. Na capital da França, tornou-se amigo de d'Alembert, Turgot e Voltaire, expoentes do iluminismo francês. Em 1774, foi nomeado Inspetor das Moedas, por Turgot, então ministro-geral das Finanças do rei Luís XVI. O Marquês, destacando-se no campo científico como matemático, foi eleito para a Academia Francesa, em 1782. Desde o anúncio da convocação dos Estados Gerais, Condorcet inicia-se numa intensa atividade política, que só terminará com a sua morte, em junho de 1794. Durante todo esse período, colaborou com vários jornais e periódicos, debatendo os problemas científicos, políticos e educacionais de seu tempo. Perseguido pelo Terror, em 1794, Condorcet refugiou-se, mas acabou sendo preso. Ele morreu em 1794, na prisão, não se sabe, ao certo, se de um colapso, envenenamento ou suicídio (Badinter, 1988).
} 
processo de civilização ao mesmo tempo em que esboça um quadro futuro do aperfeiçoamento humano.

Na perspectiva condorcetiana, civilizar é também formar a razão e a moral dos povos. Essa formação dar-se-ia em consonância com a marcha histórica do espírito humano. A civilização é produto dos progressos intelectuais, morais e institucionais alcançados pela humanidade. Sujeita à perfectibilidade, num contínuo processo de incremento e expansão da racionalidade, a humanidade estaria condenada a manter-se progredindo ou a perder suas conquistas. Assim, a civilização, embora sendo a expressão maior do progresso do espírito humano, estaria sempre ameaçada pela barbárie.

Caberia à instrução pública propiciar o florescimento da moralidade e da racionalidade. A moral resultaria de uma instrução adequada, que promovesse o desenvolvimento equilibrado das capacidades emocionais e cognitivas, e que tornasse a pessoa apta a se preocupar com o destino da humanidade e não apenas com o seu próprio interesse, de sua família ou nação.

Entre os Enciclopedistas, ao quais Condorcet estava ligado, a idéia de civilização é correlata do processo de educação do gênero humano. Seguindo Diderot, o autor propõe uma instrução livre, racional e ampliada para todos, como uma forma de promover a civilização das luzes. Assim, ele estabelece um sentido liberal para a avaliação da instrução pública.

\section{CIVILIZAÇÃO E MODERNIDADE}

Não há um consenso ou pensamento iluminista único. O que se pode fazer para traçar um padrão de pensamento do Século das Luzes é escolher alguns temas redundantes e mostrar como se alteram as formas em que são enfocados de uma linhagem filosófica para outra. As divergências apresentam-se, sobretudo, nas diferentes concepções de natureza, de política, de história e da própria razão. $\mathrm{O}$ rótulo de Iluminismo, costuma-se referir a pensadores díspares como Locke, Smith, Rousseau, Montesquieu, Diderot, D'Alembert, Voltaire, Condorcet, Benthan e Kant. Poder-se-ia, contudo, encontrar, em cada autor, um específico ideário de modernidade. Destacam-se desde os defensores dos despotismos até os que propõem uma democracia radical.

O elemento comum entre tais pensadores é a idéia de ilustração ou esclarecimento, que ficou lapidada no sapere aude kantiano, ou seja, o desafio de servir-se do próprio entendimento, de superar a minoridade intelectual e de alcançar autonomia moral. Na perspectiva da reflexão 
cartesiana, trata-se de superar os condicionamentos intelectuais e os preconceitos adquiridos através da educação, durante a infância. Mas, mesmo em torno do conceito de esclarecimento, a polêmica é infindável.

$\mathrm{O}$ reconhecimento da necessidade de universalização do esclarecimento por meio de uma instrução pública adequada aos princípios racionais não foi uniforme, nem, muito menos, unânime. Basta ver o debate entre Rousseau e os Enciclopedistas a respeito dos valores inerentes à ciência e à tecnologia, a polêmica entre Helvécios e Diderot sobre a educação, as idéias elitistas de Voltaire sobre a instrução nacional e, numa perspectiva mais ampla do iluminismo, as diferenças entre a razão prática de Kant e o utilitarismo de Benthan. Os critérios de civilização recebem diferentes valores entre os iluministas.

O movimento filosófico em torno da publicação da Enciclopédia (1751-1780) formou um núcleo em que concepções e valores da civilização foram partilhados por diferentes pensadores do Iluminismo francês, dos quais Rousseau tornou-se o mais eloqüente opositor, em especial com sua suspeita e crítica aos supostos benefícios morais trazidos pelo progresso das ciências e das artes.

Um dos aspectos característicos do ideário de civilização iluminista é o propósito de ampliar a liberdade humana. A razão estaria a serviço da emancipação, não podendo ser compreendida moralmente fora desse escopo. Conforme esse projeto de emancipação, o mundo civilizado adquire diversas feições. Contudo, alguns aspectos estão sempre presentes, tais como, a racionalização da sociedade, a idéia de um espaço público laico, a tolerância, a confiança na ciência e na técnica, e a convicção sobre a irresistível tendência da humanidade ao progresso econômico, político e moral.

Instruir e civilizar são formas de inserir os indivíduos no processo de modernização das sociedades ocidentais. Historicamente, esse processo é marcado pela racionalização, ampliação e sofisticação dos usos das tecnologias, que invadiram todos os campos da existência, em especial das organizações sociais, desde os setores produtivos, que se tornaram cada vez mais padronizados, até os setores administrativos públicos, onde a burocratização se intensificou. A ciência tornou-se o índice dessa modernização, em especial na sua acepção positivista. Ela passou a produzir os especialistas capazes de estabelecer os padrões para a ampliação da produção, para o controle de trabalhadores e para o ordenamento jurídico das instituições sociais. Daí a aspiração moderna a um saber capaz de unificar teoria e prática, gerador e legitimador das tecnociências. 
Na perspectiva filosófica, o ideário modernizador é um paradigma de civilização construído ou auto-instituído pelas sociedades ocidentais para se pensar os rumos da humanidade. Ele é um crivo para se propor e questionar as opções dos povos. De acordo com Starobinski, o termo civilização traz em si um teor crítico desde as suas origens. A reflexibilidade da civilização torna, para ela, o factual e o ideal imbricados. A civilização, como evento histórico, põe-se como índice de si mesma, e, enquanto tal, não pode deixar de reconhecer em si mesma a barbárie, seu contrário a ser superado. Ela é uma norma político-moral, um critério para se julgar a barbárie, mas enquanto fato histórico, como civilização industrial, ela torna-se um dado submetido à crítica. A cisão se dá entre a ambigüidade de seu sentido: suas acepções de direito e de fato (Starobinski, 1989, p. 53).

A modernidade, na perspectiva iluminista, tal como esta costuma ser divulgada, diz respeito ao processo de civilização ocidental, que se daria de modo homogêneo, progressista e unilinear. Civilizar significa tornar-se polido, culto, urbanizado, cortês, tolerante e hospitaleiro. A civilização é, sobretudo, a condição dos povos que adotam o Estado de Direito, e vivem com prosperidade e bem-estar material e social. Trata-se, na expressão de Starobinski, de um termo unificador que sintetizaria uma multiplicidade de idéias 2 . O progresso econômico e o avanço científico e tecnológico são meios e resultados da civilização. Eles são meios porque permitem implementar os valores reguladores, de impor o Estado de Direito, e, com este, de fazer valer a soberania nacional e, sobretudo, promover o crescimento da riqueza, conforme as regras dadas pelas ciências econômicas. A realização desses valores, por sua vez, amplia as condições do progresso técnico e científico. A modernidade, em especial

\footnotetext{
2 Sobre a origem do termo civilização, a obra Le remède dans le mal de J. Starobinski é fundamental. São destacáveis as raízes jurídicas do termo e o amplo uso do mesmo durante o período revolucionário na França. Para o autor, paradoxalmente, esse termo carrega uma conotação religiosa mesmo em suas acepções mais atéias, como é o caso de Condorcet: "La pensée des Lumières, telle qu'elle s'exprime dans l'Esquisse (1794) de Condorcet, condamme la conquête coloniale, et surtout le prosélytisme des missions chrétiennes d'outre-mer. Les épithètes tradicionnellement reservées aux barbares ('sanguinaires', 'tyranniques', 'stupides') s'appliquent aux colonisateurs, aux missionaires, à ceux qui, sur l'ancien continent, restent attacheés aux anciennes 'superstitions'. Mais une nouvelle tache apparaît: éduquer, émanciper, civiliser. Le sacré de la civilisation prend la rèleve du sacré de la religion Cependant, le texte de Condorcet montre très clairemnt que l'objetif ultime reste le même: la résorption et la disparition des autres cultures au sein de la catholicité des Lumières prennent le relais de l'entreprise missionnaire qui avait cherché à rassembler l'humanité entière sous la bannière du Christ" (Starobinski, 1989, p. 34-35).
} 
com as revoluções do século XVIII, caracteriza-se pela transformação permanente de idéias e instituições. ${ }^{3}$

Elias (1993) destaca uma característica fundamental da civilização para se compreender os seus aspectos sociológicos, culturais e políticos, mas também pedagógico e moral. Para ele, o conceito de civilização pode ser compreendido a partir do processo de restrição e autocontrole das emoções em público, que envolve as maneiras de ser, o nível e o tipo de conhecimentos adquiridos, as concepções religiosas, bem como as formas de casamento. Nesse processo, está em jogo a auto-imagem que as sociedades fazem de si mesmas.

"A moderação das emoções espontâneas, o controle dos sentimentos, a ampliação do espaço mental além do momento presente, levando em conta o passado e o futuro, o hábito de ligar os fatos em cadeias de causa e efeito - todos estes são distintos aspectos da mesma transformação de conduta, que necessariamente ocorre com a monopolização da violência física e a extensão das cadeias da ação e interdependência social. Ocorre uma mudança 'civilizadora' do comportamento." (Elias, 1993, p. 198)

O processo civilizador correlaciona a transformação interna da conduta com a expansão dos mecanismos políticos de controle social. Esse processo de controle e de mudança de "hábitos" estaria na raiz da formação do Estado Nacional, que se tornou instância básica de administração dos fatores de agregação social. A modernidade proposta pelo Iluminismo refere-se à mudança de hábito no sentido de promover um novo modelo de convivência social, que se acredita melhor, mais avançado, mais culto e mais condizente com a "verdadeira" natureza humana. O papel da instrução nesse processo é fundamental.

\footnotetext{
3 "O passado passa a ser visto como tempo de superstição e ignorância cujas autoridades devem ser abolidas. Este novo sentido da história está simbolizado na 'Revolução Francesa' que, diferentemente de todas as revoluções anteriores, significava a criação de algo completamente novo, o início de uma nova era da história. Além disso, os novos tempos, iniciados pela Revolução deveriam ser tempos de revolução permanente de idéias e instituições. (...) a própria modernidade já era vista como uma fase muito avançada da humanidade na qual culminavam os esforços do homem de domínio e controle da natureza e da própria história. O homem sentia-se, finalmente, no caminho correto do progresso e da perfeição" (Goergen, 2001, p. 14).
} 
O projeto de modernidade expressa uma proposta de formação do sujeito racional, autônomo, capaz de superar os limites de sua primeira educação definida pelo contexto sociocultural no qual o indivíduo surge ${ }^{4}$. O sujeito moderno é correlato da concepção de um mundo regido por leis racionais e inteligíveis. $\mathrm{O}$ advento do sujeito humano identifica-se então com um programa de educação baseado no ideal de florescimento do pensamento racional e de resistência às pressões do hábito e do desejo que desviam o indivíduo de uma vida conforme sua natureza de ser racional.

A autonomia racional constitui o ideal moral moderno. Para Condorcet, essa autonomia só pode florescer no interior de uma nação civilizada, em que a coletividade, à semelhança do indivíduo, torna-se um ente moral autônomo e decide de forma racional, a partir de procedimentos constitucionais, de instituições políticas justas e da promoção de um sistema de instrução pública orientada pelo progresso do espírito humano e sua especial expressão no avanço do conhecimento científico. A política constitui-se no processo de formação de uma coletividade soberana, capaz de manter as condições de seu próprio progresso ou aperfeiçoamento científico, produtivo, técnico, institucional e moral, enfim, de promover a "felicidade" e a prosperidade de uma coletividade nacional.

\section{CIVILIZAR E INSTRUIR}

Segundo Diderot (1966), a instrução “abranda as índoles, esclarece sobre os deveres, torna os vícios sutis, os oculta ou os encobre, inspira amor à ordem, à justiça e às virtudes, e acelera o nascimento do bom gosto em todas as coisas boas da vida" (p. 429-430). Segundo os Enciclopedistas, dos quais Diderot foi o maior expoente, não haveria possibilidade da saída do homem da barbárie sem a mediação da instrução. Para os iluministas franceses, a crítica que se faz à violência, inerente ao processo de imposição dos valores civilizados aos povos "bárbaros" ou primitivos, baseia-se num falso dilema. Não se poderia, do ponto de vista moral, questionar se deve

\footnotetext{
4 "O que vale para a sociedade vale para o indivíduo. Sua educação deve ser uma disciplina que o liberte de uma visão estreita, irracional, que lhe impõem a família e suas paixões, e o abra ao conhecimento racional e a participação em uma sociedade que a ação da ração organiza (momento revolucionário). A escola deve ser o lugar de ruptura com o meio de origem e abertura ao progresso, ao mesmo tempo pelo conhecimento e pela participação em uma sociedade fundada em princípios racionais. O professor intervém na vida privada das crianças, que não devem ser outra coisa a não ser alunos, ele é um mediador entre eles e os valores universais da verdade, do bem e do belo. A escola deve também substituir os privilégios herdados de um passado rejeitado por uma elite recrutada através de provas impessoais realizadas através de concursos" (Touraine, 1998, p. 20).
} 
ou não promover a civilização, como fez Rousseau. A este respeito, diz D'Alembert.

“Trata-se, portanto, de saber unicamente se um cidadão, nascido e criado entre os povos civilizados, aí é mais ou menos feliz que um selvagem nascido e criado entre seus semelhantes. O consentimento dos homens parece ter decidido essa questão pelo fato; a maioria entre eles acreditou que lhe seria mais vantajoso viver nos estados civilizados, e não podemos acusar o gênero humano de ser cego a respeito de suas verdadeiras vantagens." (1965, p. 228)

O Enciclopedista admite que a modernidade, inerente ao processo de civilização, traz as vantagens materiais, espirituais e morais aos homens. Mas a civilização exigiria um grau mínimo de cultura e de conhecimento por parte dos indivíduos que compõem as sociedades polidas. Não se trata mais, para D'Alembert, de discutir se se deve ensinar ou não os modos civilizados, mas de "examinar até onde esses conhecimentos devem ser levados" (1965, p. 228-229).

A civilização, mesmo quando leva a uma ruptura cultural radical, seria um fenômeno positivo. Portanto, para os filósofos em questão, como expressa D'Alembert, não haveria mal em romper a "ligação natural dos homens, a maneira de viver que eles adquiriram desde a infância" (1965, p. 228). As idéias de humanidade e civilização, como foram concebidas pelos iluministas, especialmente expressadas nas palavras de D'Alembert, contrapõem-se a qualquer possibilidade de educação baseada na diferença, seja ela comunitária, pluralista ou multicultural. Tal modelo de formação humana seria visto apenas como forma de perpetuar preconceitos, tradições e saberes ultrapassados. Esse tipo de educação, na perspectiva Enciclopedista, apenas contribuiria para a corrupção da "verdadeira" moral.

Conforme o ideal iluminista de civilização, em nome da unidade do gênero humano, as manifestações culturais regionais devem ser superadas por um processo de instrução capaz de levar os povos dos mais diversos cantos do mundo a se organizarem e agirem conforme à universalidade da natureza humana, à racionalidade e às conquistas das ciências e da técnica. No Plan d'une Université pour le Gouvernement de Russie, Diderot deixa clara a correlação entre instrução e civilização. "Instruir uma nação, diz este autor, é civilizá-la" (1966, p.429). A civilização sempre acompanharia o avanço da ciência e da técnica. Sem isso, ter-se-ia a ignorância própria do selvagem e do escravo (1966, p. 429). De certa forma, a idéia de civilização retoma, como mostra Starobinski (1989, p. 34-35), o sentido do sagrado da religião. 


\section{A CIVILIZAÇÃo CONTRA A TRADIÇÃO}

Para Condorcet, embora a humanidade fosse marcada pela imperfeição (o erro, a injustiça), ela tem em si mesma o remédio para tal mal: a capacidade de progredir. A perfectibilidade é erigida como eixo fundamental da história, significando a melhoria das condições da felicidade coletiva. $O$ bem não pode ser durável se ele não faz progresso para o melhor (Condorcet, 1994, p. 68). Essa idéia de bem se aplicaria a tudo que é susceptível de progresso. A instrução é o processo pelo qual a humanidade preserva suas conquistas e prepara novos avanços. Ela é ao mesmo tempo condição e resultado da perfectibilidade. O homem é susceptível de ser instruído porque é perfectível. A própria educação progride porque os saberes avançam. Os saberes avançam impulsionados pela ampliação da liberdade como expressão da perfectibilidade econômica e política. Esta, por sua vez, garante as condições do progresso. O ensino é o meio de promover a humanidade, de aperfeiçoá-la. Na instrução, encontram-se imbricadas as dimensões ética, política e epistemológica. Através da civilização todo o gênero humano se unificaria do ponto de vista jurídico, econômico, político e mesmo cultural, pois a razão é a mesma por todos os lados. A instrução destaca-se como o lócus da ação mais intencional. Ela seria prioritária para promover os valores da civilização.

A concepção de modernidade de Condorcet está em conformidade com o ideário iluminista de combater a tradição como fonte de legitimidade política e como valor moral. A moral fundar-se-ia em princípios inegáveis para qualquer pessoa racional. Como lembra MacIntyre, o Iluminismo visou prover

"o debate público de padrões e métodos de justificação racional através dos quais cursos de ação alternativos, em cada esfera da vida, pudessem ser julgados justos ou injustos, racionais ou irracionais, esclarecidos ou não-esclarecidos. Assim, esperava-se que a razão tomaria lugar da autoridade e da tradição." (1994, p.16)

Condorcet destaca que isso foi possível graças a pensadores como Descartes e Bacon, que foram os primeiros modernos a propor um método para purificar o espírito, preparando-o para buscar rigorosamente a verdade. $O$ autor propõe levar às últimas conseqüências esses ensinamentos, ou seja, aplicá-los não só à ciência, mas também à moral. Isso supõe a possibilidade de preparo do espírito humano para estar sempre alerta contra tudo que poderia sedimentar-se nele, de modo a desvirtuá-lo de sua capacidade de produzir a verdade, evitar o erro e, conseqüentemente, de bem agir. Trata-se de combater a tradição, a moral fundada no acaso da comunicação desordenada dos saberes acumulados 
pelo costume desvirtuado. Este compreenderia, sobretudo, os erros ou saberes que foram válidos para determinadas situações anteriores e continuam sendo aceitos mesmo depois de não serem mais eficazes ou não terem mais sentido, devido à própria mudança das condições dos povos.

A crítica à tradição é feita em sua conexão com a educação. Segundo Condorcet, "o homem comum recebe dos outros suas opiniões, suas paixões, seu caráter; ele retém tudo das leis, dos preconceitos, dos costumes de seu país, como a planta recebe tudo do solo que a nutre e do ar que a rodeia" (1968, IV, p. 3-4). Observando esse homem comum, aprender-se-ia apenas "o império ao qual a natureza nos submeteu, e não o segredo de nossas forças e as leis de nossa inteligência" (1968, IV, p. 3-4). Condorcet propõe que o indivíduo tome as rédeas de sua educação. Em vista disso, o filósofo concebe o sistema de instrução pública como um instrumento crítico para se superar os preconceitos e a autoridade da tradição, que possibilitasse a cada um "refazer de alguma modo sua própria razão" (1988, p. 208). Se a razão é igual por todos os lados, não haveria motivo para que os princípios fundamentais do ensino fossem diversos ou plurais.

Os princípios constituintes da civilização em Condorcet são a razão, a tolerância e a humanidade (1988, p. 227). A razão deve ser a base objetiva de todas as escolhas. Em concordância com a razão comum está o princípio da tolerância. Este nega qualquer tipo de discriminação, seja censitária, de gênero ou de credo religioso. São os princípios racionais, científicos, e não a superstição e a ignorância, que deveriam definir os critérios da expressão da coletividade e da instrução pública. A tolerância só pode ocorrer quando a razão for o único princípio orientador da vida política, pois só a racionalidade expressaria, mais veemente, a dimensão universal do gênero humano. As injunções públicas das diferentes concepções religiosas e morais tradicionais seriam suprimidas na medida em que o progresso da instrução comum promovesse o avanço da razão.

Como condição prévia da tolerância, está a ampliação da moral nacional para abranger toda a humanidade. Um dos principais critérios da justiça política estaria na universalidade de sua aplicação. O objetivo da justiça seria o de eliminar toda forma de opressão em todos os cantos da terra. A razão sendo única e igual em todo o ser humano tornaria esse ideal não só realizável, mas um dever dos "amigos da humanidade" e da justiça.

Para Condorcet, ao contrário do particularismo inerente às diversas tradições locais, a racionalidade científica constitui-se na expressão universal do espírito humano. Assim, o espírito analítico cartesiano, que revolucionou as ciências matemáticas e naturais e permitiu o desenvolvimento do cálculo das probabilidades, quando aplicado às ciências morais, possibilitaria também formar a razão e a moral dos povos. 


\section{INSTRUÇÃO E CIDADANIA}

No que concerne à justiça, conforme propõe Condorcet, caberia ao ensino público contribuir para a diminuição do intervalo entre os direitos que a lei reconhece aos cidadãos e os direitos dos quais eles têm um gozo real (1988, p. 271). A emancipação não pressupõe a igualdade social entre os indivíduos, mas sim a universalização do gozo dos direitos naturais e da cidadania. As diferenças em termos de capacidade, de disposição intelectual e econômica produziriam desigualdades entre os indivíduos. Mas certas igualdades são fundamentais para se garantir a liberdade, tais como, a igualdade de direitos entre homens e mulheres, brancos e negros e a igualdade de instrução pública básica. Para Condorcet, a racionalidade e suas prerrogativas não são propriedades dos indivíduos masculinos, brancos, europeus, etc. Ele foi um ativo combatente das discriminações e opressões justificadas na suposta superioridade de gênero ou de cor da pele. As desigualdades admitidas seriam aquelas que "comprovadamente" produzissem prosperidade comum, e que não resultassem apenas em privilégios produzidos pela "arte social", pela política. Cabe a esta fazer com que as desigualdades presumidas como naturais não gerassem dominação. Esse é o desafio da política, que só seria dispensável quando isso fosse uma realidade definitiva.

A questão da justiça envolveria a todos os cidadãos, pois todos são responsáveis pelas leis que definem restrições aos indivíduos, pela definição dos comandos da razão comum. O sistema político condorcetiano liga-se intimamente à ampliação da instrução pública e da cidadania. Em última instância, as leis estabelecidas dependem da qualidade moral e epistemológica do ensino nacional. $\mathrm{O}$ objetivo da formação da cidadania, da "razão e da moral de um povo" não é o de louvar e mistificar uma Constituição nacional, mas de avaliá-la e corrigi-la (1994, p. 93). A legislação, numa nação instruída, não se tornaria eficaz pela mera amplitude da submissão à lei, mas pela autonomia que ela permite à coletividade que esta sendo regulada ${ }^{5}$. A racionalidade da lei, numa sociedade perfectível, produz uma legitimação aberta, diferentemente da força da tradição.

\footnotetext{
5 Il ne sagit pas de soumettre chaque génération aux opinions comme à la volonté de celle que la précéde, mais de les éclarer de plus en plus, afin de chacun devienne de plus en plus digne de se gouverner par sa propre raison." (MacIntyre, 1994, p. 93) 


\section{CONSIDERAÇÕES FINAIS}

A civilização expande-se com a proliferação dos meios de comunicação. Condorcet foi um entusiasta das possibilidades trazidas pelo uso da imprensa, no sentido de promover o progresso, a justiça e a cidadania. Contudo, para ele, o progresso da comunicação carrega consigo a possibilidade de dominação como de emancipação dos indivíduos. Ele supõe que se pode corromper a razão e a moral de um povo a tal ponto que, mesmo numa democracia, o povo poderia, livremente, escolher sua opressão, e preferir a barbárie à civilização.

A idéia de civilização condorcetiana baseia-se numa moral que não coloca o bárbaro como um outro a ser combatido devido a sua nacionalidade, costume, religião, mas o concebe como elemento interno à própria civilização, como aqueles que são os inimigos do progresso do gênero humano. Os bárbaros são os que se beneficiam econômica e politicamente da estagnação da perfectibilidade da espécie humana.

A tradição não poderia ser a autoridade orientadora de um povo, mas a razão. Ao contrário da tradição, admite Condorcet, a razão não é um legado despótico que deve ser recebido sem exame, mas é a própria capacidade de examinar e nada pode escapar ao seu crivo, nem mesmo as normas que ela admite como universais. Para ser fiel a Descartes e a Montesquieu, é necessário submeter tudo à razão, tal como eles o fizeram, mesmo que, para isso, seja necessário superá-los.

"Se eles destruíram obstáculos que se opunham ao progresso das Luzes, eles criam novos, mas o reconhecimento posterior deve continuar o mesmo, por que eles ensinaram a vencer esses obstáculos que os próprios fizeram nascer, ao darem o exemplo de tudo submeter à razão." (Condorcet, 1986, p. 329)

A razão é capaz de rever seus veredictos, conforme o avanço do espírito humano mostra suas incoerências ou a necessidade de se substituir às normas que foram instituídas para uma situação que não existe mais. Portanto, uma geração não deveria governar ou estabelecer as normas para a outra. É nesse sentido, que na filosofia de Condorcet, o progresso resulta da superação racional da tradição, que se expressa nas instituições de uma nação. Instruir é exercer a perfectibilidade individual e coletiva do espírito humano.

Uma instrução capaz de formar indivíduos críticos, com capacidade de pensamento analítico, culturalmente descentrados e abertos para o respeito à racionalidade como valor universal, torna-se cada vez mais "ultrapassada" para quem defende as novas tendências curriculares, que buscam os valores multiculturais, o resgate das identidades específicas, o 
desenvolvimento da afetividade e das inteligências múltiplas. Trata-se de uma tendência recente de educadores que visam a adaptar-se a um mundo em que a hegemonia do capitalismo não se funda mais no ideário iluminista.

Com os currículos de ensino baseados nos direitos das minorias e no resgate das culturas e tradições locais, conforme tem se verificado nas propostas comunitaristas, perde-se cada vez mais o foco da idéia de gênero humano e de sua unidade racional. Se os iluministas foram radicais em sua proposta de civilização, a ponto de negarem as singularidades culturais, a tendência de afirmar as diferenças não nos livra de um recrudescimento da barbárie em suas faces econômica, política e moral. O relativismo, igualmente ou não ao universalismo, pode ser opressivo. Do mesmo modo, ambos podem contribuir para a emancipação, para combater a estupidez, a miséria e o sofrimento. A emancipação humana não é determinada necessariamente nem por uma nem por outra tendência.

O que presenciamos atualmente é uma dissociação cada vez mais acentuada entre progresso da ciência e da tecnologia, da racionalidade, da instrução pública, dos valores da civilização e da moral universalista, entendida como a capacidade de agir de forma racional, empática e solidária. Essa dissociação é o principal sintoma da crise do projeto iluminista.

O que os iluministas não "tematizaram" é que eles estavam fundando uma nova tradição baseada num ethos universalista, racional, analítico e individualista. Ao salientarem o movimento iluminista como antitradicionalista, eles concebiam a tradição como fonte de erro, preconceito e apegos a "valores" próprios de um passado que não faz mais sentido. A lógica do comunitarismo ao rejeitar o prisma iluminista, o nega enquanto tradição hegemônica ocidental. Com isso, a razão envolve-se num curto-circuito. Nega-se o iluminismo como uma tradição negadora da tradição ${ }^{6}$. Contudo, se não podemos escapar de nossas tradições, tão cedo não poderemos nos livrar dos valores iluministas, a menos que mudemos o sentido da tradição ou façamos referência a uma outra tradição à qual não pertencemos. Mas isso não nos livra da armadilha da ficção do Barão de Munschhausen, da tentativa inútil de arrancar-se do atoleiro arrastando-se pelos próprios cabelos. Enfim, como podemos renegar o legado iluminista sem cairmos em novas barbáries?

${ }^{6}$ Isso reflete o que Taylor (1996, p. 39) denomina de tradição "of living home" dos americanos: "(...) we can talk without paradox of an American 'tradition of leaving home. The young person learns the independent stance, but this stance involves is defined by the culture, in a continuing conversion into which that young person is inducted (and in which the meaning of independence can also alter with the time)." 


\section{REFERÊNCIAS BIBLIOGRÁFICAS}

BADINTER, E. et R. Condorcet un intellectuel en politique. Paris: Fayard, 1988.

CONDORCET, M. (Jean-Antoine Nicolas de Caritat) Oeuvres (Ed. A Condorcet O'Connor et M F Arago, 1847). Stuttgard: Friedrich Frommann Verlag (Reimpressão), 1968.

. Sur les élections. Paris: Fayard, 1986.

- Esquisse d'un tableau historiques des progress de l'esprit humain.

Fragment sur l'atlantide. Paris: GG-Flammarion, 1988.

1994.

. Cinq mémoires sur l'instruction publique. Paris: GF-Flammarion,

D'ALEMBERT, J. Essai sur les éléments de philosophie. Hildesheim (Alem.): Geog OLMS Verlagsbuchhandlung, 1965.

DIDEROT, D. Oeuvres Completes. Paris: Assezat, J. Touneux, 1966.

ELIAS, N. O processo civilizador. Rio de Janeiro: Jorge Zahar, v. 2, 1993.

GOERGEN, P. Pós-modernidade, ética e educação. São Paulo: Autores Associados, 2001.

MACINTYRE, A. Justiça de quem? Qual racionalidade? São Paulo: Loyola, 1994.

STAROBINSKI, J. Le remède dans le mal: Critique et legitimation de l'artifice a l'age des Lumières. Paris: Galimard, 1989.

TAYLOR, C. Sources of self. Cambridge: Cambridge University Press, 1996.

TOURAINE, A. Crítica da modernidade. Rio de Janeiro: Vozes, 1998.

Recebido em: outubro 2002

Aprovado para publicação em: julho 2004 
